\title{
AVALIAÇÃO DOS RESULTADOS OBTIDOS COM O PROJETO DE REESTRUTURAÇÃO DO ENSINO E PRÁTICA DA PESQUISA E PROSPECÇÃO MINERAL NO IFRN - PRIMEIRA E SEGUNDA PARTE
}

\author{
Matheus Lisboa Nobre da Silva \\ Bolsista ITI-B do Grupo de Pesquisa Mineral do IFRN \\ E-mail: nobre.mt@gmail.com \\ Mário Tavares de Oliveira Cavalcanti Neto \\ Professor do IFRN e Coordenador do Grupo de Pesquisa Mineral \\ Diretoria de Educação e Tecnologia de Recursos Naturais - IFRN Campus Natal Central \\ E-mail:mario@cefetrn.br
}

\section{RESUMO}

O Projeto de "Reestruturação do Ensino e Prática da Pesquisa e Prospecção Mineral no IFRN", primeira e segunda parte, respectivamente em 2008 e 2009, foi elaborado com o apoio da Pró-Reitoria de Pesquisa e Inivação do IFRN e está sendo realizado visando atender a demanda do mercado por profissionais consoantes com as técnicas de Pesquisa e Prospecção Mineral contemporâneas. Essa demanda foi mais enfática com o retorno do curso de Geologia, separado do curso de Mineração, com entrada da primeira turma para o próximo semestre letivo 2010.1. A primeira parte do Projeto visou disponibilizar material didático-pedagógico destinado exclusivamente para Técnicos de Geologia e Mineração, tendo sido elaborado uma página na INTERNET (http://www.pesquisamineralcefet.hpg.com.br/) e um Livro (no prelo). A segunda parte, em curso, objetiva a recuperação e aquisição de equipamentos de Geologia e Geofísica e a seleção de áreas próximas à Natal, visando baratear os custos e aumentar a quantidade de aulas de campo.

PALAVRAS-CHAVE: IFRN, Geologia, Pesquisa Mineral, Prospecção Mineral, Geofísica. 


\section{AVALIAÇÃO DOS RESULTADOS OBTIDOS COM O PROJETO DE REESTRUTURAÇÃO DO ENSINO E PRÁTICA DA PESQUISA E PROSPECÇÃO MINERAL NO IFRN - PRIMEIRA E SEGUNDA PARTE}

\section{INTRODUÇÃO}

O projeto de "Reestruturação do ensino e prática da Pesquisa e Prospecção Mineral no IFRN" teve início no ano de 2008 com sua primeira etapa. Nessa fase, foram realizadas diversas atividades pelo Grupo de Pesquisa Mineral da instituição, entre as quais estão:

- a implementação do site da disciplina (www.pesquisamineralcefet.hpg.com.br), que hoje é fonte de pesquisa e estudo de alunos, professores e pesquisadores em geral, inclusive de outras instituições brasileiras;

- a conclusão do livro "Noções de Pesquisa e Prospecção Mineral", escrito numa colaboração entre os professores Mário Tavares e Alexandre Rocha. Esse será o primeiro livro destinado aos técnicos de Geologia e Mineração;

- a obtenção de espaço físico provisório para desenvolvimento das atividades;

- o levantamento inicial acerca do potencial didático de áreas próximas à Grande Natal;

- e a publicação de artigos em Congressos de Iniciação Científica e na revista HOLOS.

Na segunda etapa, desenvolvida em 2009, procurou-se atuar em duas vertentes, sendo uma de manutenção das realizações da primeira etapa e a outra de implementação de melhorias. A segunda parte do projeto engloba:

- o inventário de equipamentos de Geofísica, para que se tenha maquinário adequado à prática de campo e a realização de pesquisas;

- a operacionalização de alguns equipamentos catalogados, inclusive pelos alunos;

- a implementação de aulas de reforço eletrônico;

- a conclusão do levantamento de potencial didático das áreas próximas à Grande Natal;

- a utilização de novos softwares de Geologia, Geoquímica e Geofísica, notadamente o Oasis Montaj 6.4.1;

- a documentação em Mídia, especialmente filmagem de atividades de campo, inclusive em empresas e sua disponibilização na INTERNET;

- a elaboração de Projetos de Pesquisa, sendo um para o CNPq e outro para a FINEP;

- a integração com equipe do DG/UFRN, laboratório LARANA, visando a aprendizagem da manipulação de equipamentos de radiometria como o emanômetro Alpha Guard e Gama-espectômetro;

- e a publicação de artigos no CONNEPI 2009 (Belém/PA), Revista HOLOS, EXPOTEC e Simpósio de Geologia do Nordeste.

\section{A DISCIPLINA}

Por definição, Pesquisa e Prospecção Mineral (PPM) é um conjunto de atividades e técnicas que visa à descoberta, o estudo e a avaliação de Depósitos Minerais (MARANHÃO, 1989). Inclui conhecimentos relativos à Estatística, Topografia, Geodésia, 
Informática Aplicada, Gerenciamento de Banco de Dados, aplicações de software SIG/GIS, Cartografia, Mineralogia, Química e Geoquímica, Física e Geofísica, Geologia Estrutural, Depósitos Minerais, Geologia Econômica, Sondagens, Serviços Mineiros de Pesquisa Mineral, entre outros.

\section{METODOLOGIA}

A metodologia aplicada no projeto é reflexo da diversidade disciplinar que a Pesquisa e Prospecção Mineral possui. A multiplicidade de ações, então, procura englobar conteúdos que compõem a matriz curricular do aluno de Geologia e Mineração no IFRN.

\section{Inventário dos equipamentos geofísicos}

O IFRN possui diversos equipamentos geofísicos, no entanto, a maior parte deles encontrava-se sem uso e com problemas de funcionamento. O Grupo de Pesquisa Mineral catalogou os principais. Entre eles estão:

- 1 (um) magnetômetro ENVI de precessão de prótons, produzido pela SCINTREX;

- 2 (dois) magnetômetros C-304-AE, produzido por Detectron;

- 3 (três) magnetômetros de efeito Overhauser, produzido pela GEM Systems;

- 2 (dois) sensores de raio gama 825012, produzido pela SCINTREX;

- entre outros.

Com os dados colhidos, gerou-se uma tabela, usando o software Microsoft EXCEL. Os dados inseridos continham informações de localização espacial do equipamento (usando a nomenclatura DEPXX, em que DEP indica "Depósito" e XX o número do equipamento na tabela, e SGPMXX, em que SGPM indica "Sala do Grupo de Pesquisa Mineral" e XX o número do equipamento na tabela), modelo, número de série e outras observações relevantes, como informações acerca do funcionamento.

Tabela I - Parte da tabela de catalogação dos equipamentos.

\begin{tabular}{|c|c|c|c|c|}
\hline Identificador & Equipamento & Marca & Modelo & Serial \\
\hline DEP 01 & Espectrômetro & SCINTREX & 807018 & 8203356 \\
\hline DEP 02 & Espectrômetro & Geometrics & DISA 300 & \\
\hline SGPM 03.1 & Magnetômetro & Geometrics (?) & Unimag II & \\
\hline SGPM 03.2 & Magnetômetro & Geometrics (?) & Unimag II & \\
\hline SGPM 04.1 & Magnetômetro & Geometrics & G 816 & \\
\hline SGPM 04.2 & Magnetômetro & Geometrics & G $816 / 826 A$ & \\
\hline SGPM 04.3 & Magnetômetro & Geometrics & $\mathrm{G} 816$ & \\
\hline SGPM 05.1 & Magnetômetro & Detectron & C-304-AE & \\
\hline SGPM 05.2 & Magnetômetro & Detectron & C-304-AE & \\
\hline SGPM 06.1 & Magnetômetro Overhouser & GEM Systems & GSM-19 & $3624-4$ \\
\hline SGPM 06.2 & Magnetômetro Overhouser & GEM Systems & GSM-19 & $3624-7$ \\
\hline SGPM 06.3 & Magnetômetro Overhouser & GEM Systems & GSM-19 & $3624-8$ \\
\hline SGPM 07 & Magnetômetro ENVI & SCINTREX & & 9611158 \\
\hline
\end{tabular}

Além da catalogação utilizando a tabela, como recurso visual, foram tiradas diversas fotografias dos equipamentos, para ser montado posteriormente um catálogo com os equipamentos geofísicos disponíveis no Instituto. 


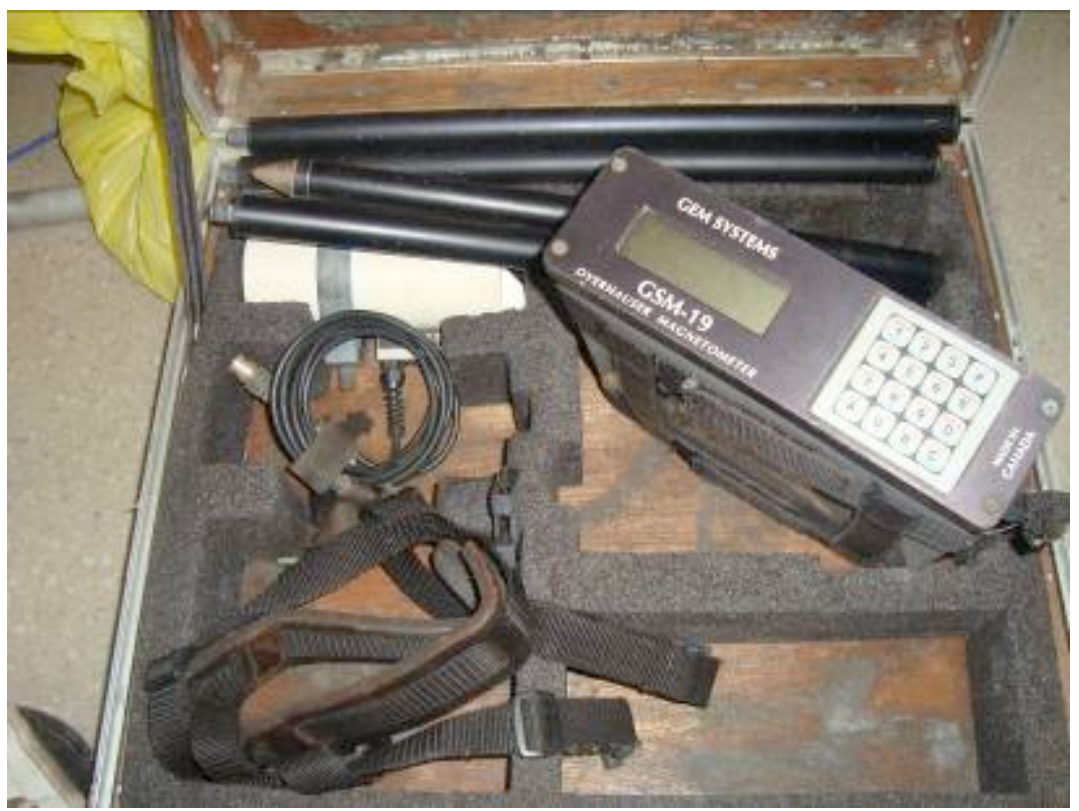

Figura 1 - Magnetômetro de efeito Overhauser (GEM Systems) catalogado pelo projeto.

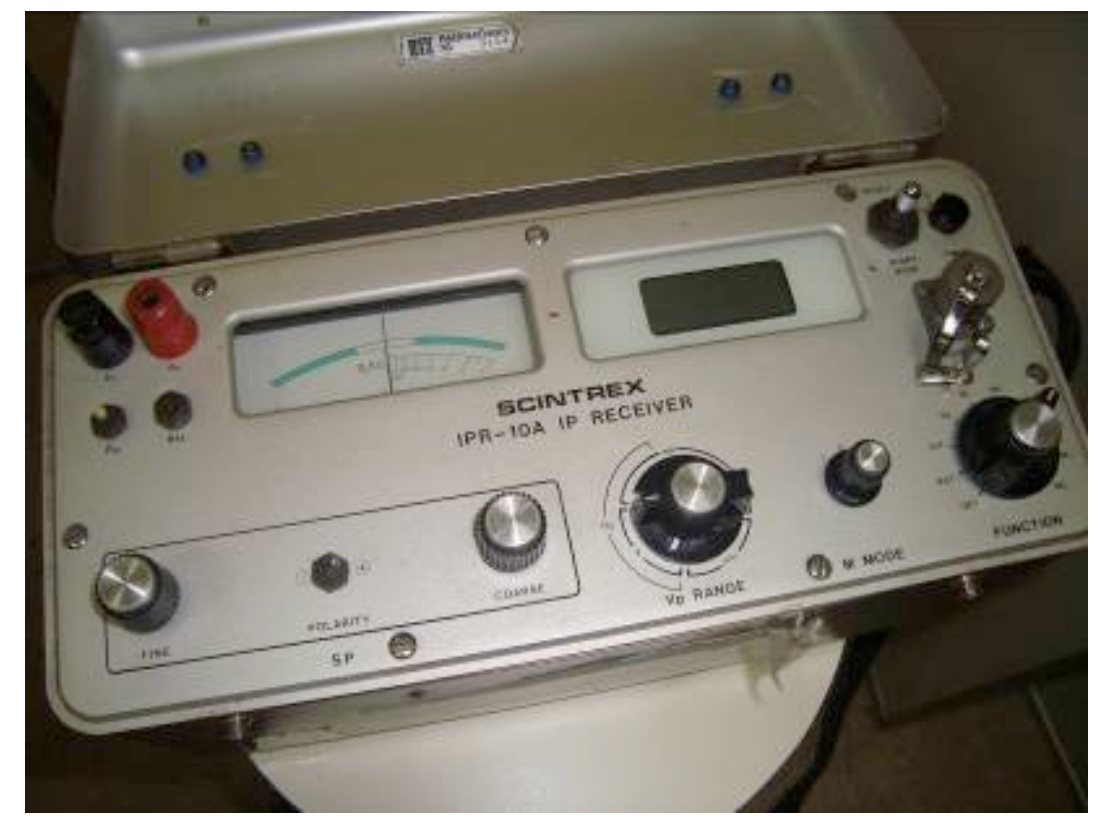

Figura 2 - Receptor de IP, IPR-10A (SCINTREX) catalogado pelo projeto.

\section{Implementação de aulas de reforço}

Junto à catalogação dos equipamentos geofísicos, ampliou-se a utilização da "Sala de Reforço Eletrônico", localizada no andar térreo da Diretoria de Educação e Tecnologia de Recursos Naturais (DIETREN). Em vídeos produzidos pelo Grupo de Pesquisa ou doados por empresas, como a Vale, o aluno pode esclarecer dúvidas sobre o conteúdo e enriquecer seus conhecimentos acerca de Geofísica, Geoquímica, MapInfo, GPS e Bússola. Além dos vídeos, o bolsista do Grupo encontra-se capaz de solucionar problemas, junto aos estudantes, de operação de softwares SIG/GIS e instrumentação geofísica. 


\section{Operacionalização dos equipamentos catalogados}

Após a catalogação, iniciou-se o processo de operacionalização de alguns desses equipamentos, a fim de se fazer uso deles para a prática de Pesquisa Mineral junto aos alunos.

Com a colaboração dos professores de física do IFRN, conseguiu-se a operacionalização de 2 (dois) magnetômetros de efeito Overhauser (GEM Systems). Tais equipamentos foram utilizados em um levantamento magnetométrico no campus Natal-Central do Instituto.

\section{Desenvolvimento de métodos geofísicos junto aos alunos}

Com a recuperação de dois magnetômetros GSM-19 e um SCINTREX, além do cintilômetro geoMetrics, foram disponibilizados aos alunos equipamentos geofísicos para a realização de práticas de campo. Consoantes com a Linha de Pesquisa "Geofísica Ambiental" do Grupo de Pesquisa Mineral, e trabalhando-se com docentes de outras áreas, num trabalho multidisciplinar, foi realizado um levantamento cintilométrico e magnetométrico do campus Natal-Central do IFRN, o qual foi objeto de exposição na EXPOTEC 2009.

Inicialmente, utilizando uma planta do campus georreferenciada, planejou-se uma malha única para ambos os levantamentos. Essa malha conta com 6 linhas distanciadas 50 metros, no rumo $\mathrm{S} 25,3^{\circ} \mathrm{W}$, com estações de medições a cada 33,4 metros. No total, a malha é composta de 48 estações. As medições magnetométricas ainda contaram com 30 pontos de observações, extras à malha, para cobrir espaços com prováveis anomalias magnetométricas que não haviam sido celebradas na malha planejada. Tais medidas de observação foram feitas em espaços como: laboratórios de informática, mecânica e edificações; Núcleo de Inovação Tecnológica (NIT); biblioteca; marcenaria; agência da Caixa Econômica Federal; entre outros.

O levantamento magnetométrico, fazendo uso de magnetômetros de efeito Overhauser (GEM Systems), aplicou o método de estações base e móvel, com a aquisição de dados base para que fosse feita a correção diurna dos dados coletados nas estações de medição e pontos de observação.

O levantamento cintilométrico, utilizando um cintilômetro GR-101A (geoMetrics), foi realizado com a aquisição de dados através de medições únicas nas estações planejadas na malha. 


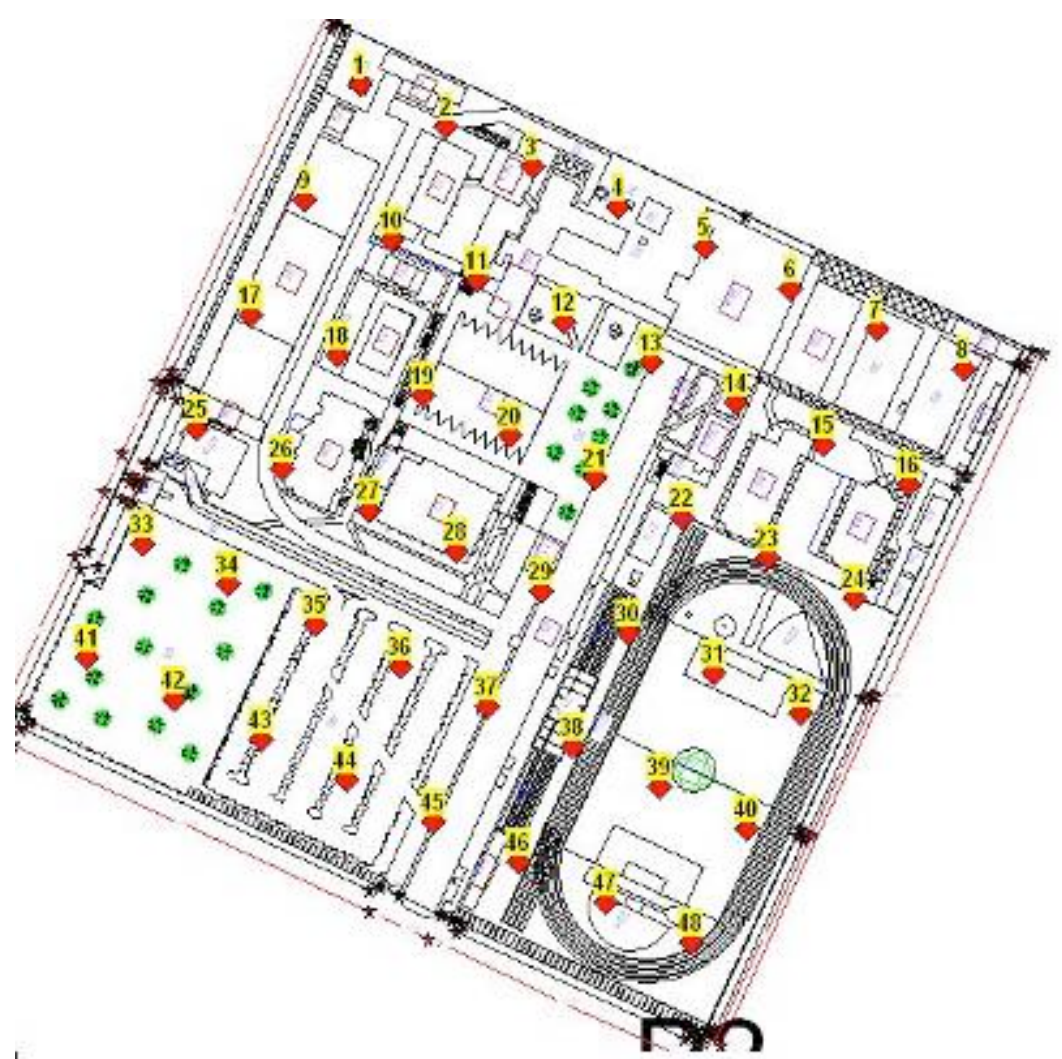

Figura 3 - Malha planejada para os levantamentos magnetométrico e cintilométrico no campus Natal-Central do IFRN.

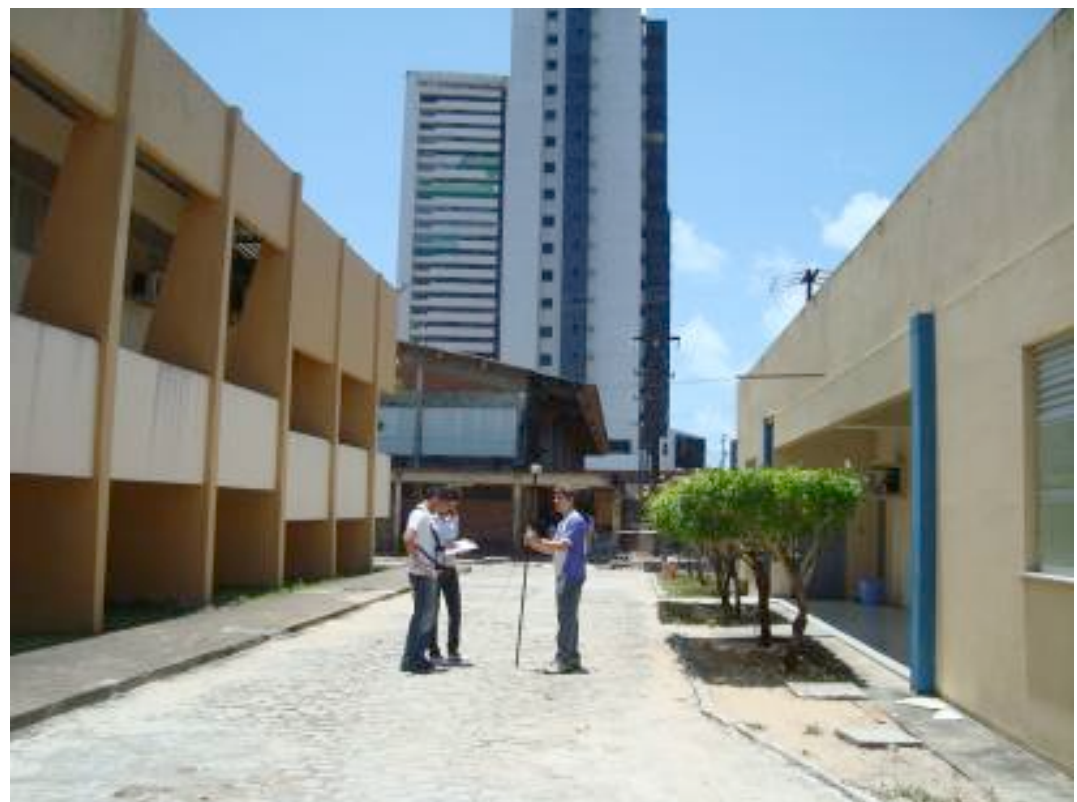

Figura 4 - Alunos realizando medição magnetométrica.

Os levantamentos no IFRN tiveram por objetivo principal a prática de conceitos da Pesquisa e Prospecção Mineral através de métodos geofísicos. Como objetivo secundário, teve-se a aplicação desses métodos às ciências ambientais, uma vez que o objeto do estudo passou a ser não possíveis minerais de importância econômica e/ou geológica, mas a interação do ambiente com os seres humanos e suas tecnologias. 
Um dos interesses dos levantamentos passou a ser a influência da atividade humana no campo magnético local, com o aumento de campos magnéticos artificiais, resultados da intensa aplicação de materiais ferromagnéticos em objetos e estruturas presentes no campus e no cotidiano das pessoas, como computadores, vigas metálicas, detectores magnéticos, celulares, etc. A partir disso, criou-se um estudo mais aprofundado da influência de campos magnéticos artificiais na saúde humana, como o aparecimento da Síndrome da Deficiência do Campo Magnético (SALGADO, 2009) e a incidência crescente de problemas cardíacos (PRIETO, 2007), aliada à diminuição da força do campo magnético terrestre pelo aquecimento global, consequência da atividade humana (HUMPHREYS, 2002).

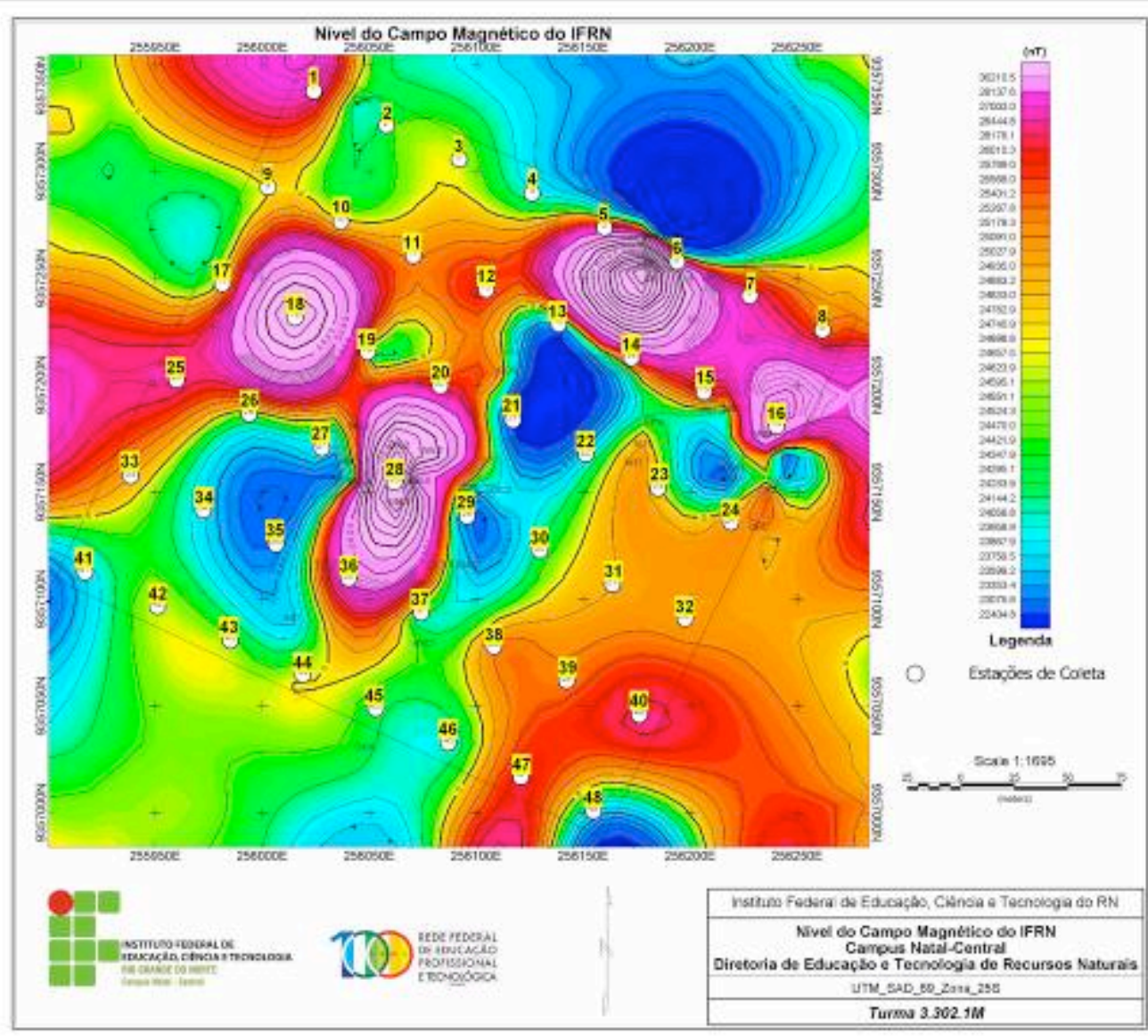

Figura 5 - Mapa de campo magnético medido no campus Natal-Central do IFRN (escala 1:1695), elaborado pela turma 2009.3.302.1M.

Outro interesse do trabalho foi a atividade radioativa no campus e as conseqüências à saúde pela exposição a altos níveis radioativos, como: anemias, cancros, úlceras, tumores, atrofia muscular e paralisia. 


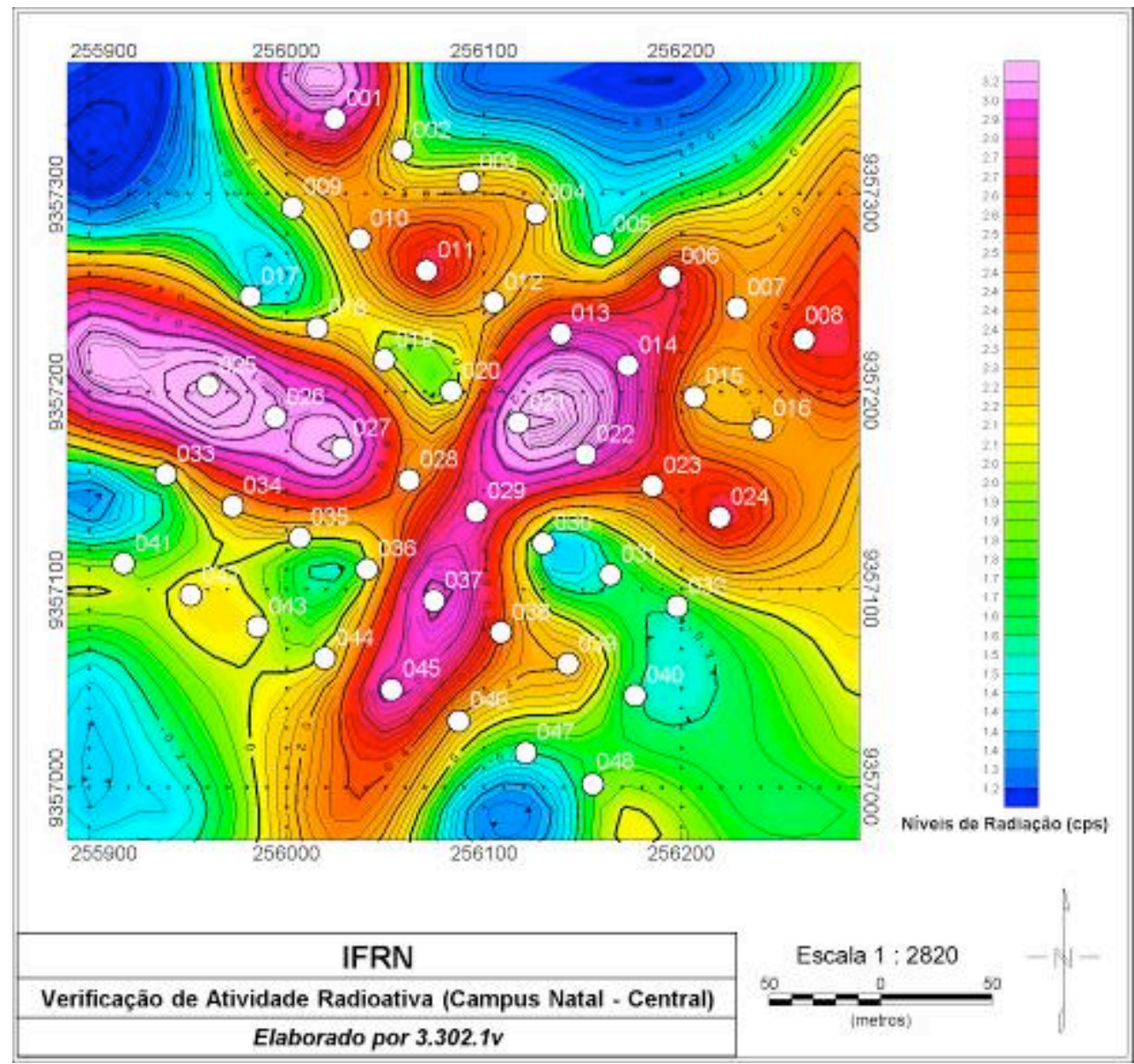

Figura 6 - Mapa de atividade radioativa medida no campus Natal-Central do IFRN (escala 1:2820), elaborado pela turma 2009.3.302.1V.

\section{Levantamento do potencial didático de áreas próximas à Grande Natal}

A partir do Mapa Geológico do Estado do Rio Grande do Norte (CPRM, 2006), foram selecionadas áreas próximas à cidade de Natal que apresentassem diversidade litológica e ocorrência ou probabilidade de ocorrência de mineralizações. Em seguida foi realizada uma etapa de campo visando avaliar a qualidade das exposições litológicas e a logística de acesso, tendo em vista que as aulas de campo serão realizadas com ônibus ou micro-ônibus com limitações de tráfego em certas rodovias.

As áreas selecionadas estão, no máximo, $60 \mathrm{~km}$ distantes do campus Natal-Central, numa região que está sendo re-interpretada a luz de novos dados geocronológicos definindo um novo domínio, denominado por alguns autores de Domínio São José do Campestre (DSJC), do Arqueano.

Este Domínio é limitado a Oeste pela Zona de Cisalhamento Picui-João Câmara (ZCPJC) e a Oeste pela Bacia Potiguar (Formação Açu e Formação Jandaira), Sedimentos do Grupo Barreiras e terraços eluviais terciários e aluviões quaternários. No DSJC são reconhecidos também resquícios de representantes da Faixa Seridó (mais notadamente xistos), BIF (Banded Iron Formation), "skarns", ultrabásicas, granitóides e pegmatóides de diversas gerações e idades. 
Os recursos minerais atualmente conhecidos são: areia para construção civil, caulim, brita, diatomito, argila, calcário, ferro, scheelita, coríndon, esmeralda, petróleo e gás.

Apesar de pouco estudada, e utilizando critérios de associações geoquímicas, estruturas presentes, similaridade com outros ambientes geológicos e o conceito de Metallotectes, poder-se-ia esperar ainda mineralizações de $\mathrm{Cr}$, $\mathrm{Ni}, \mathrm{Au}, \mathrm{Li}$, berilo, água marinha, molibdenita, cassiterita, U+Th, P entre outras.

A distância da sede possibilita o pernoite em Natal, eliminado os custos com hospedagem e de, pelo menos, uma alimentação (jantar). Com essas reduções acreditamos ser possível um aumento na quantidade de aulas práticas e, ao mesmo tempo, um barateamento das mesmas.

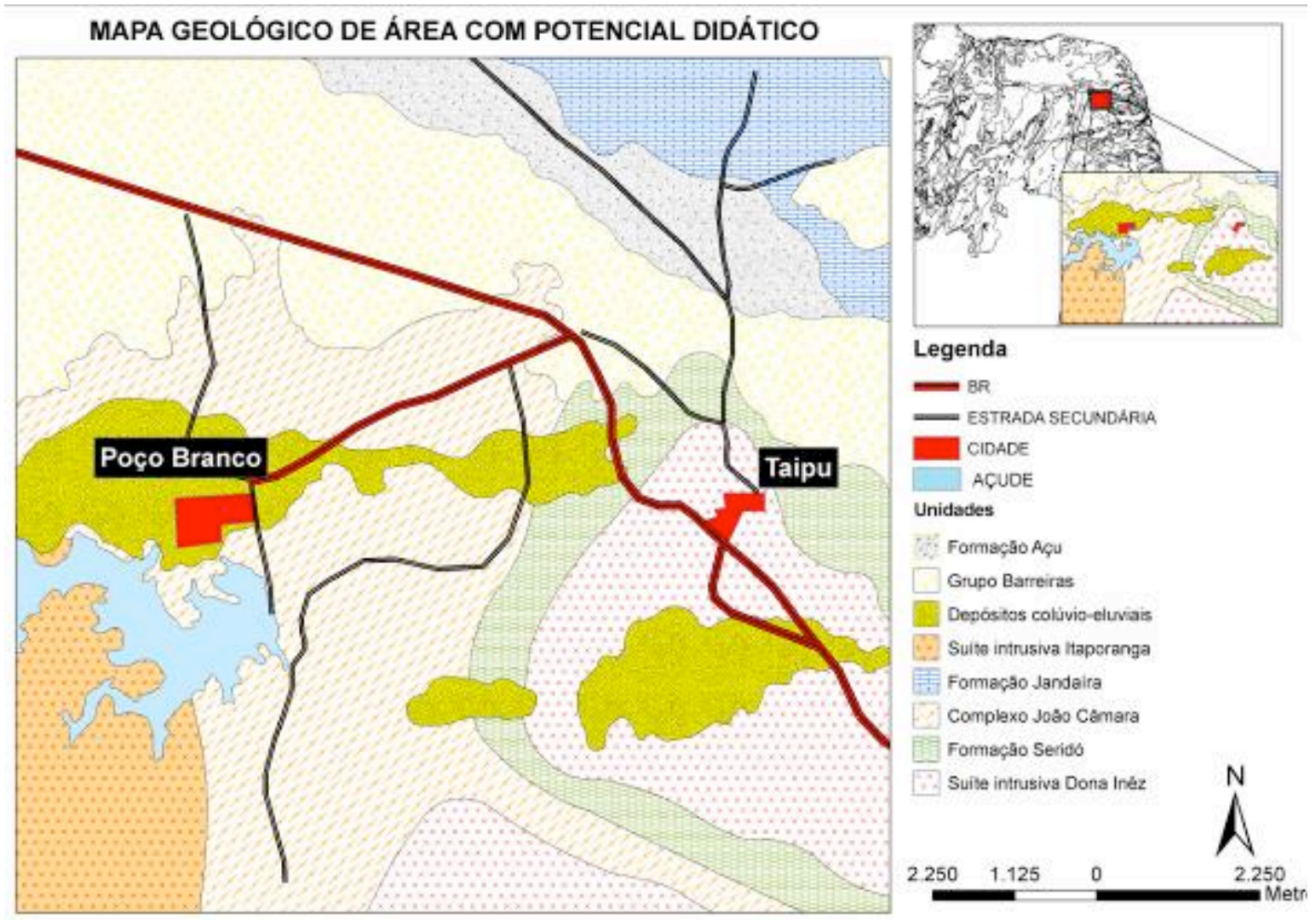

Figura 7 - Mapa geológico da área de pesquisa de potencial didático para a realização de aulas de campo.

\section{NOVOS OBJETIVOS}

Com a evolução tecnológica e a descoberta de fontes importantes de estudo, como o présal, é necessário que a disciplina de Pesquisa e Prospecção Mineral seja desenvolvida no IFRN periodicamente com o intuito de manter-se como forte meio de aprendizagem para os alunos do curso de Geologia.

É preciso, portanto, uma atualização constante dos docentes de forma a desenvolver ainda mais o curso e seus alunos. Diversificar o ensino e promover nos estudantes a procura pela pesquisa científica, visando o melhoramento de seu conhecimento próprio, como também da instituição. 


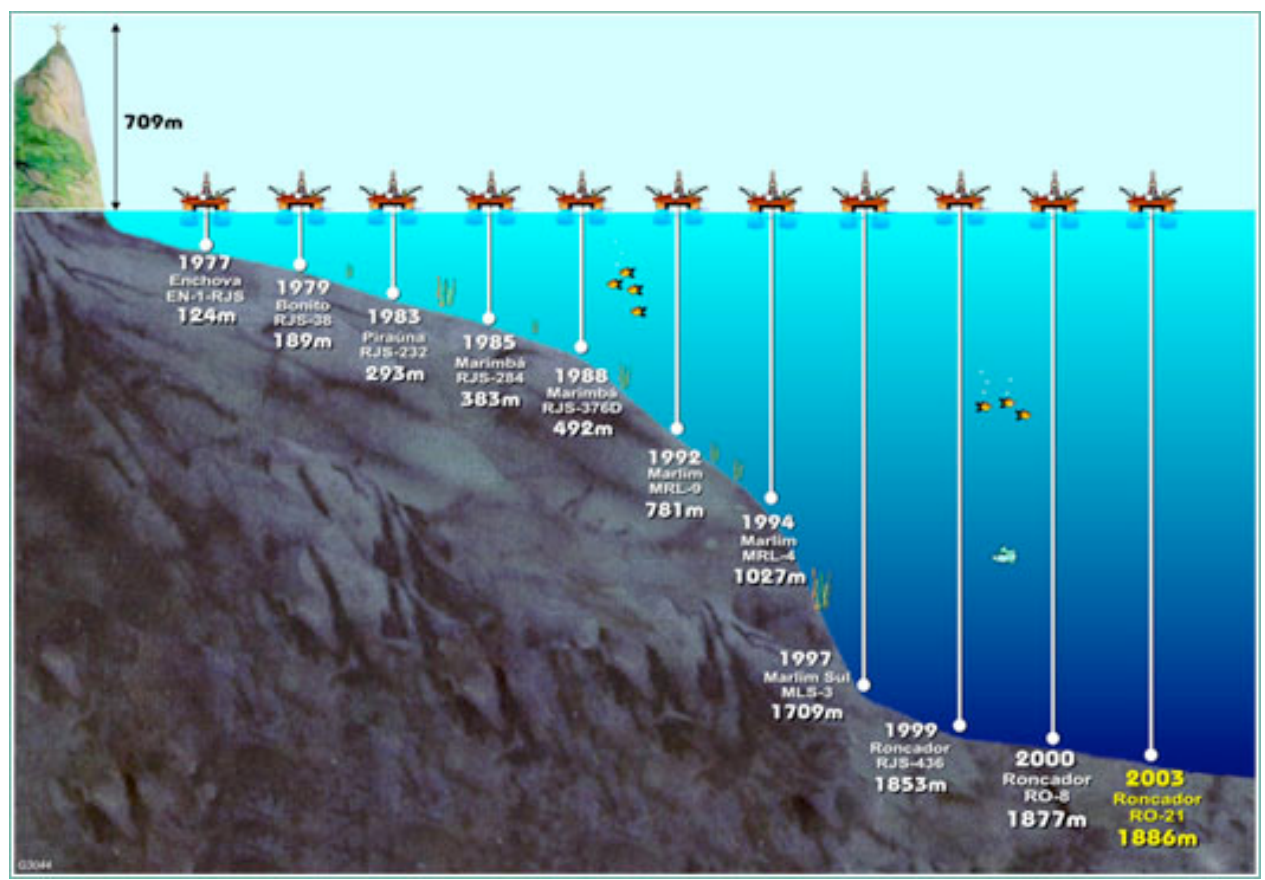

Figura 8 - Evolução da profundidade de exploração de petróleo em águas profundas. $O$ petróleo é uma das fontes de pesquisa tecnológica mais rentável didática e economicamente. (fonte: Petrobras)

O petróleo é a grande fonte de riqueza dos séculos XX e XXI e é potencialmente explorável didaticamente no curso de Geologia. O petróleo, junto à descoberta da camada pré-sal, deve ser o grande desafio e objetivo de estudo da disciplina de Pesquisa e Prospecção Mineral, como também de toda a matriz curricular do curso, uma vez que ele tem uma grande importância para o desenvolvimento do país. Profissionais formados com conhecimentos nessa área serão mais bem vistos pelo mercado num futuro próximo. Muitos investimentos em tecnologia e pesquisa serão feitos a partir desse momento. É preciso, então, que o IFRN, através de seu curso na área, não seja ultrapassado por outras instituições a fim de possuir uma continuidade de suas atividades nas próximas décadas. Para tanto, deve-se investir no conhecimento e pesquisa na área. Esse deve ser o principal objetivo do ensino e prática da disciplina de Pesquisa e Prospecção Mineral no Instituto Federal de Educação, Ciência e Tecnologia do Rio Grande do Norte.

\section{CONCLUSÕES E RECOMENDAÇÕES}

O principal resultado do projeto de "Reestruturação do Ensino e Prática da Pesquisa e Prospecção Mineral no IFRN", em suas duas etapas, foi a consolidação de um grupo de atividade na área da Pesquisa Mineral e a implantação, ainda que modesta, de uma base infra-estrutural mais adequada para as atividades do recém-criado curso técnico de Geologia.

Recomenda-se que as atividades subseqüentes contemplem o engajamento de um maior número de professores nos projetos de Pesquisa do Grupo de Pesquisa Mineral, consolidação de algumas Linhas de Pesquisa implantadas e em implantação, fortalecimento de ações multi e interdisciplinares, atualização e aperfeiçoamento dos 
docentes e aquisição de novos equipamentos. Outra vertente recomendada é a promoção de maior sinergia com empresas e instituições financiadoras de estudos e pesquisas visando assimilar novos conhecimentos, financiamentos e pesquisas.

\section{REFERÊNCIAS}

CAVALCANTI Nt, Mário Tavares de Oliveira; ROCHA da ROCHA, Alexandre Magno; BARBOSA, Rogério Vidal Nunes Barbosa; AOQUI, Milton Issashi; MAIA, Marcos Aurélio de Oliveira. Projeto de elaboração de um livro didático para a disciplina Prospecção e Pesquisa Mineral. In: Congresso de Iniciação Científica do CEFET-RN CONGIC. Natal: CEFET-RN, 2008.

CAVALCANTI Nt, Mário Tavares de Oliveira; ROCHA da ROCHA, Alexandre Magno. Noções de Pesquisa e Prospecção Mineral para Técnicos de Geologia e Mineração. (no prelo)

CPRM (Companhia de Pesquisa de Recursos Minerais). Mapa Geológico do Estado do Rio Grande do Norte. Rel., Texto Explicativo, Natal RN, 2006.

HUMPHREYS, D. Russel. The Earth's Magnetic Field is Still Losing Energy. CRS Quartery, Vol 39, No 1, June 2002.

IAEG - INTERNATIONAL ATOMIC ENERGY AGENCY. International Basic Safety Standards for Protection against Ionizing Radiation and for the Safety of Radiation Sources Safety Series No. 115, 1996.

MARANHÃO, R.J.L (1989) - Introdução à Pesquisa Mineral, 4ª ed., Banco do Nordeste do Brasil, ETENE, Fortaleza, 796p.

PRIETO, José Antonio. Las tormentas que provocan infartos fulminantes. Diario Disponible en: <http://www.diariosalud.net/content/view/4734/413/> Acceso en: 12 Set 2009.

SALGADO, Rita de Cássica Falleito; MACUDO, Maria Iliano Borba. Equilíbrio Bioenergético Através do Biomagnetismo - Relato de um Grupo de Estudo. In: ENCONTRO PARANAENSE, CONGRESSO BRASILEIRO DE PSICOTERAPIAS CORPORAIS, XIV, IX, 2009. Anais. Curitiba: Centro Reichiano, 2009. 